\title{
The spectrum of renal thrombotic microangiopathy in lupus nephritis
}

\author{
Di Song ${ }^{1}$, Li-hua Wu ${ }^{1,2}$, Feng-mei Wang ${ }^{1}$, Xiao-wei Yang ${ }^{1}$, Di Zhu ${ }^{1}$, Min Chen ${ }^{1}$, Feng Yu ${ }^{1 *}$, Gang Liu ${ }^{1}$ and \\ Ming-hui Zhao'
}

\begin{abstract}
Introduction: Among various lupus renal vascular changes, thrombotic microangiopathy (TMA) presented with the most severe clinical manifestations and high mortality. The pathogenesis of TMA in systemic lupus erythematosus (SLE) was complicated. The aim of this study was to assess clinical manifestations, laboratory characteristics, pathological features and risk factors for clinical outcomes of lupus nephritis patients co-existing with renal TMA in a large cohort in China.
\end{abstract}

Methods: Clinical and renal histopathological data of 148 patients with biopsy-proven lupus nephritis were retrospectively analyzed. Serum complement factor $\mathrm{H}$, A Disintegrin and Metalloprotease with Thrombospondin type I repeats 13 (ADAMTS-13) activity, antiphospholipid antibodies and C4d deposition on renal vessels were further detected and analyzed.

Results: In the 148 patients with lupus nephritis, 36 patients were diagnosed as co-existing with renal TMA based on pathological diagnosis. Among the 36 TMA patients, their clinical diagnoses of renal TMA were as followings: 2 patients combining with thrombotic thrombocytopenic purpura-hemolytic uremic syndrome, 2 patients combining with anti-phospholipid syndrome, 2 patients with malignant hypertension, 1 patient with scleroderma and the other 29 patients presenting with isolated renal TMA. Compared with the non-renal TMA group, patients with renal TMA had significantly higher urine protein $(7.09 \pm 4.64$ vs. $4.75 \pm 3.13 \mathrm{~g} / 24 \mathrm{~h}, P=$ $0.007)$ and serum creatinine $(159,86$ to $215 \mathrm{vs} .81,68$ to $112 \mu \mathrm{mol} / \mathrm{l}, P<0.001)$, higher scores of total activity indices (AI) $(P<0.001)$, endocapillary hypercellularity $(P<0.001)$, subendothelial hyaline deposits $(P=0.003)$, interstitial inflammation $(P=0.005)$, glomerular leukocyte infiltration $(P=0.006)$, total chronicity indices $(C I)(P=$ 0.033), tubular atrophy $(P=0.004)$ and interstitial fibrosis $(P=0.018)$. Patients with renal TMA presented with poorer renal outcome $(P=0.005)$ compared with the non-TMA group. Renal TMA (hazard ratio (HR): $2.772,95 \%$ confidence interval: 1.009 to $7.617, P=0.048$ ) was an independent risk factor for renal outcome in patients with lupus nephritis. The renal outcome was poorer for those with both $C 4 \mathrm{~d}$ deposition and decreased serum complement factor $\mathrm{H}$ in the TMA group $(P=0.007)$.

Conclusions: There were various causes of renal TMA in lupus nephritis. Complement over-activation via both classical and alternative pathways might play an important role in the pathogenesis of renal TMA in lupus nephritis.

\footnotetext{
* Correspondence: yufengevert1@sina.com

${ }^{1}$ Renal Division, Department of Medicine, Peking University, First Hospital, Peking University Institute of Nephrology, Key Laboratory of Renal Disease, Ministry of Health of China, Key Laboratory of Chronic Kidney Disease Prevention and Treatment, Ministry of Education of China, Beijing 100034, PR China

Full list of author information is available at the end of the article
}

\section{Biomed Central}

(C) 2013 Song et al.; licensee BioMed Central Ltd. This is an open access article distributed under the terms of the Creative Commons Attribution License (http://creativecommons.org/licenses/by/2.0), which permits unrestricted use, distribution, and reproduction in any medium, provided the original work is properly cited. 


\section{Introduction}

Renal involvement is common in systemic lupus erythematosus (SLE) [1]. In addition to glomerulonephritis, the status of renal vascular lesions is also important in lupus nephritis because their presence can adversely affect the prognosis of the renal disease [2,3]. Among various lupus renal vascular changes, thrombotic microangiopathy (TMA) presented with the most severe clinical manifestations and high mortality [4]. Since the pathogenesis of TMA in lupus nephritis is complex and unclear, detailed descriptions about it were lacking in the literature.

In fact, TMA in lupus nephritis consisted of a group of diseases, including anti-phospholipid syndrome (APS), thrombotic thrombocytopenic purpura-hemolytic uremic syndrome (TTP-HUS), scleroderma, malignant hypertension and calcineurin inhibitor-associated thrombotic microangiopathy and so on. The pathogenesis of TMA in SLE was complicated. Recently, Danielle et al. demonstrated that activation of the complement classical pathway might be a crucial factor in the development of TMA in lupus nephritis [5].

The aim of this study was to assess clinical manifestations, laboratory characteristics, pathological features and risk factors for clinical outcomes of patients with TMA in lupus nephritis in a large cohort of Chinese patients. The roles of A Disintegrin and Metalloprotease with Thrombospondin type I repeats 13 (ADAMTS-13), complement factor $\mathrm{H}$, antiphospholipid antibodies and $\mathrm{C} 4 \mathrm{~d}$ deposition in renal vessels were further evaluated.

\section{Methods}

\section{Patients}

Clinical and renal histopathological data of 148 patients with renal biopsy-proven lupus nephritis, diagnosed between May 2002 and July 2008 in Peking University First Hospital were reviewed.

\section{Clinical evaluation and definitions of the diseases and lesions}

All the included patients fulfilled the 1997 American College of Rheumatology revised criteria for SLE [6]. The disease activity was assessed by the Systemic Lupus Erythematosus Disease Activity Index (SLEDAI) $[7,8]$.

TTP-HUS was characterized by microangiopathic hemolytic anemia and thrombocytopenia and/or fever and/or acute renal impairment and/or neurologic impairment. APS was defined by the Sapporo criteria [9].

Renal TMA was defined as interlobular artery, arteriole and glomerular capillary lesions, including endothelial cell swelling, lumen narrowing or obliteration and thrombi formation by light microscopy. Swelling of glomerular endothelial cells, detachment from the glomerular basement membrane and widening of the subendothelial space were identified by electron microscopy (Additional file 1, Figure S1A, B). No striated fine fibrillary structure or other specific structure of cryoglobulinemic glomerulonephritis was identified by electron microscopy. The lesions were divided into acute changes and chronic changes [5]. The acute lesion was defined as the presence of at least one fibrin microthrombus (conformed by fibrin and CD61 staining), either in glomeruli, or in small arterioles and/or arteries (Additional file 2, Figure S2A, B). Chronic changes were mucoid changes and onion skin lesions of arterioles and/or arteries (Additional file 2, Figure S2C).

The response to therapy includes complete remission, partial remission and treatment failure detailed in previous works [10-13]. The indications for plasma exchange was as follows: lupus nephritis with crescentic glomerulonephritis, fibrinoid necrosis and thrombotic microangiopathy in renal pathological changes, severe extra-renal involvement, such as central nervous system injury, hematological abnormalities, cardiovascular diseases, catastrophic antiphospholipid antibody syndrome and so on [14].

A relapse was defined as: 1 ) nephritic relapse: a recent increase of serum creatinine by $>50 \%$ with active urinary sediments; 2) proteinuric relapse: development of either a nephrotic syndrome (proteinuria $>3.5 \mathrm{~g} /$ day and serum albumin $<30 \mathrm{~g} / \mathrm{L}$ ) or proteinuria $>1.5 \mathrm{~g} /$ day without other causes, in previously non-proteinuric patients $[15,16]$.

The patients were followed up in outpatient clinics specified for lupus nephritis. The primary end point was defined as death and the secondary end point was defined as end stage renal disease (ESRD) or doubling of serum creatinine.

\section{Laboratory assessment}

The following laboratory features were further detected using serum at the day of renal biopsy.

Serum antinuclear antibodies (ANA) were detected using indirect immunofluorescence assay (EUROIMMUN, Lübeck, Germany) and anti-double-stranded DNA (ds-DNA) antibodies were detected using Crithidia luciliae indirect immunofluorescence test (EUROIMMUN, Lübeck, Germany). Anti-extractable nuclear antigen (ENA) antibodies, including anti-Sm, anti-SSA, anti-SSB and anti-RNP antibodies, were detected using immunodotting assay (EUROIMMUN, Lübeck, Germany). Anti-cardiolipin antibodies and anti- $\beta 2$ GP- 1 antibodies were detected using enzyme-linked immunosorbent assay (ELISA) (EUROIMMUN, Lübeck, Germany). Serum C3 was determined using rate nephelometry assay (Beckman-Coulter, IMMAGE, Brea, California, USA, normal range $>0.85 \mathrm{~g} / \mathrm{L}$ ). Serum cryoglobulins were detected by spectrophotometry (Beckman-Coulter, IMMAGE, Brea, California, USA). 


\section{Quantification of serum complement factor $\mathrm{H}$}

The method to detect serum complement factor $\mathrm{H}(\mathrm{CFH})$ was the same as previously described [17], with mild modification. Serial concentrations of commercial available highly purified human factor $\mathrm{H}$ from $1,050 \mu \mathrm{g} / \mathrm{ml}$ to $16.4 \mu \mathrm{g} / \mathrm{ml}$ were used to develop the standard curve. The $\mathrm{CFH}$ level of each sample was calculated using Curve expert 1.3 (Hyams DG, Starkville, Mississippi, USA). The linear portion of the curve was subsequently used for the measurement of serum factor $\mathrm{H}$. All assays were run in duplicate, and when standard errors were over $10 \%$, samples were routinely re-analyzed.

\section{Detection of serum ADAMTS-13 activity}

The ADAMTS-13 activity assay was the same as previously described [18]. Data were analyzed as the percentage of collagen-binding activity remaining after dialysis compared to the collagen binding activity in the individual's baseline sample. One hundred percent minus the residual collagen-binding activity was arbitrarily regarded as the ADAMTS-13 activity. Inter-assay precision was determined by evaluating single normal human plasma in 10 consecutive assay runs for ADAMTS- 13 activity determination. The inter-assay percent coefficient of variation was found to be $<10 \%$.

\section{Routine renal histopathology}

The renal biopsy specimens were routinely examined by light microscopy, direct immunofluorescence and electron microscopy techniques.

Lupus nephritis was re-classified according to the International Society of Nephrology and Renal Pathology Society (ISN/RPS) 2003 lupus nephritis classification system [19].

\section{Light microscopy examination}

Renal biopsy specimens were fixed in $4.5 \%$ buffered formaldehyde for light microscopy. Consecutive serial 3 $\mu \mathrm{m}$ sections were used for histological staining. Stains employed included hematoxylin and eosin (H\&E), periodic acid-Schiff (PAS), silver methenamine (Meth) and Masson's trichrome. Pathological parameters, such as activity indices (AI) and chronicity indices (CI), were approached by renal pathologists using a modification of a previously reported system involving semi-quantitative scoring of specific biopsy features [20,21].

\section{Direct immunofluorescence examination}

The direct immunofluorescence for immunoglobulin $G$ (IgG), immunoglobulin A (IgA), immunoglobulin M (IgM), C3, C1q and fibrin was semi-quantitatively graded from 0 to 4 according to the intensity of fluorescence, respectively.

\section{Electron microscopy examination}

Renal biopsy specimens were fixed in $2.5 \%$ paraformaldehyde for electron microscopy. After being embedded in epon, ultrathin sections were mounted on metal grids and stained with uranyl acetate before being viewed in a transmission electron microscope (JEM-1230; JEOL, Tokyo, Japan).

\section{C4d staining on renal vessels by immunohistochemistry}

Staining of C4d on renal vessels was performed by immunohistochemistry as was previously described [22]. Rabbit anti-human C4d polyclonal antibodies (Abcam, Cambridge, UK) were used as primary antibodies (dilution 1:400). As negative controls, primary antibodies were replaced by normal rabbit IgG. The sections were examined by light microscopy (Additional file 2, Figure S2D).

\section{CD61 staining in kidneys by immunohistochemistry}

The method of CD61 staining was similar to C4d [23]. Rabbit anti-human CD61 polyclonal antibodies (Zhongshan Golden Bridge Biotechnology, Beijing, China) were used as primary antibodies (dilution 1:200).

\section{Blood samples}

Sera were obtained from peripheral blood at the same day as the renal biopsy before initiation of immunosuppressive treatment. All sera samples were stored at $-80^{\circ} \mathrm{C}$ until used. Repeated freeze/thaw cycles were avoided.

Informed consent was obtained for blood sampling and renal biopsy from each patient. The research was in compliance with the Declaration of Helsinki. The design of this work was approved by the local ethical committees of Peking University First Hospital (No. 2012[470]).

\section{Statistical analysis}

Statistical software SPSS 18.0 (SPSS, Chicago, IL, USA) was used for statistical analysis. Quantitative data were expressed as mean $\pm \mathrm{SD}$, and median with range (minimum, maximum). For comparison of clinical and pathological features of patients, the Student's $t$-test, one-way ANOVA analysis of variance and Chi-square test were used. Kaplan-Meier curves were used to analyze the patients' prognoses. Survival analysis was performed using the log-rank test. Multivariate analysis with Cox regression was used to determine the prognostic factors. Results were expressed as hazard ratio (HR) with $95 \%$ confidence intervals. Statistical significance was considered as $P<0.05$.

\section{Results}

\section{General data of patients with renal TMA in lupus nephritis}

First, we analyzed the general data of patients with renal TMA in lupus nephritis (details in Table 1). Among the 148 lupus nephritis patients enrolled in this study, 36 were identified as combining with renal TMA changes by pathological findings. In the TMA group, the average age was $29.75 \pm 9.24$ (15 to 52$)$ at presentation. Ten (27.8\%) patients were male and $26(72.2 \%)$ were female, with a 
Table 1 General data of patients combined with renal TMA and lupus nephritis

\begin{tabular}{|c|c|c|c|c|c|c|c|c|}
\hline No. & $\begin{array}{c}\text { Age } \\
\text { (years) }\end{array}$ & $\begin{array}{c}\text { Clinical } \\
\text { diagnosis }\end{array}$ & $\begin{array}{l}\text { Pathological } \\
\text { types }\end{array}$ & $\mathrm{CFH}(\mu \mathrm{g} / \mathrm{ml})$ & $\mathrm{ACL}$ & Anti- $\beta 2 \mathrm{GP}-1$ & $\begin{array}{l}\text { ADAMTS-13 } \\
\text { Activity (\%) }\end{array}$ & $\begin{array}{c}\text { C4d deposition on vascular } \\
\text { wall }\end{array}$ \\
\hline 1 & 25 & $\mathrm{LN}$ & $\mathrm{IV}-\mathrm{G}(\mathrm{A} / \mathrm{C})$ & 386.0 & - & - & 88 & - \\
\hline 2 & 38 & LN & $\mathrm{IV}-\mathrm{G}(\mathrm{A} / \mathrm{C})$ & 670.2 & - & - & 83 & ++ \\
\hline 3 & 34 & LN & IV-G(A) & 166.8 & - & - & 70 & + \\
\hline 4 & 45 & $\mathrm{LN}+\mathrm{MHT}$ & IV-G(A/C) & 694.8 & - & - & 68 & - \\
\hline 5 & 28 & LN & IV-G(A/C) & 298.8 & - & - & 94 & + \\
\hline 6 & 43 & LN & $I V-G(A)+V$ & 642.8 & - & - & 75 & - \\
\hline 7 & 26 & $\begin{array}{c}\text { LN } \\
\text { +Scleroderma }\end{array}$ & IV-G(A) & 136.0 & - & - & 74 & + \\
\hline 8 & 26 & LN & $I V-G(A)+V$ & 112.8 & - & - & 95 & - \\
\hline 9 & 23 & LN & $I V-G(A)+V$ & 385.4 & - & - & 91 & + \\
\hline 10 & 27 & LN+TTP-HUS & $\mathrm{IV}-\mathrm{G}(\mathrm{A} / \mathrm{C})$ & 146.0 & - & - & 97 & + \\
\hline 11 & 32 & LN & $\|(\mathrm{A} / \mathrm{C})+\mathrm{V}$ & 467.6 & - & - & 95 & + \\
\hline 12 & 38 & $\mathrm{LN}+\mathrm{MHT}$ & $\mathrm{IV}-\mathrm{G}(\mathrm{A} / \mathrm{C})$ & 251.6 & - & - & 98 & - \\
\hline 13 & 20 & LN & IV-G(A) & 362.4 & - & - & 98 & - \\
\hline 14 & 31 & LN & IV-G(A) & 551.2 & - & - & 71 & - \\
\hline 15 & 25 & LN & $I V-G(A)$ & 567.4 & - & - & 85 & + \\
\hline 16 & 19 & LN & IV-G(A) & 620.4 & - & - & 98 & + \\
\hline 17 & 34 & LN+TTP-HUS & IV-G(A) & 365.6 & - & - & 89 & - \\
\hline 18 & 19 & LN & IV-S(A) & 457.0 & - & - & 89 & - \\
\hline 19 & 31 & LN & IV-G(A) & 491.4 & - & - & 97 & - \\
\hline 20 & 18 & LN+APS & $I V-G(A)+V$ & 162.0 & + & - & 45 & + \\
\hline 21 & 30 & LN+APS & V & 707.2 & - & + & 98 & + \\
\hline 22 & 43 & LN & $\|(A / C)+V$ & 498.8 & - & - & 96 & + \\
\hline 23 & 24 & LN & IV-G(A/C) & 222.4 & - & - & 96 & + \\
\hline 24 & 35 & LN & IV-G(A/C) & 540.0 & - & - & 99 & - \\
\hline 25 & 40 & LN & $\mathrm{IV}-\mathrm{G}(\mathrm{A} / \mathrm{C})$ & 117.8 & - & - & 98 & - \\
\hline 26 & 21 & LN & III & 201.2 & - & - & 63 & + \\
\hline 27 & 38 & LN & IV-G(A) & 672.6 & - & - & 88 & + \\
\hline 28 & 52 & LN & IV-G(A/C) & 131.0 & - & - & 96 & - \\
\hline 29 & 37 & LN & V & 340.0 & - & - & 32 & - \\
\hline 30 & 27 & LN & IV-G(A) & 124.4 & - & - & 95 & - \\
\hline 31 & 18 & LN & IV-G(A/C) & 492.8 & - & - & 95 & - \\
\hline 32 & 15 & LN & IV-G(A) & 221.2 & - & - & 97 & ++ \\
\hline 33 & 33 & LN & IV-G(A) & 374.0 & - & - & 80 & + \\
\hline 34 & 15 & LN & IV-G(A) & 407.2 & - & - & 68 & + \\
\hline 35 & 40 & LN & V & 434.2 & - & - & 96 & - \\
\hline 36 & 20 & LN & IV-G(A) & 627.6 & - & - & 97 & + \\
\hline
\end{tabular}

Note: The normal range of serum CFH was $561.3 \pm 179.7$ (381.6 to 741.0$) \mu \mathrm{g} / \mathrm{ml}$. The normal range of ADAMTS-13 activity was $95 \%$ (42\% to $99 \%$ ). Abbreviations: APS, anti-phospholipid syndrome; LN, lupus nephritis; MHT, malignant hypertension; TTP-HUS, thrombotic thrombocytopenic purpura-hemolytic uremic syndrome

male to female ratio of 1:2.6. Compared with previous studies, the ratio of renal TMA in lupus nephritis was higher.

Then, the detailed renal pathological data were analyzed. According to the 2003 classification of lupus nephritis, 3 patients were classified Class III (8.3\%, including 2 as Class III + V), 30 as Class IV $(83.3 \%, 1$ as Class IV-segmental (IV-S) (2.8\%) and 25 as Class IV-global (IV-G) (69.4\%), including 4 as Class IV-G $+\mathrm{V}$ ) and 3 as Class V (8.3\%). There was no case of Class I, Class II or Class VI in this study. Class III and IV were further subdivided into an active (A) group, active/chronic (A/C) group and chronic (C) group. Within Class III, the number of III (A) was 1, III $(\mathrm{A} / \mathrm{C})$ was 2 and III $(\mathrm{C})$ was 0 . The Class IV-S is IV-S (A). Within Class IV-G, the number of IV-G (A) was 18, IV-G (A/C) was 12 and IV-G (C) was 0. For further evaluation of renal pathological features of TMA, 17 patients presented with pure acute lesions, 6 with pure chronic lesions and 13 with both acute and chronic lesions, as described in the Methods. Among the 30 patients with acute lesions, 14 had micro-thrombi in glomeruli and 23 had micro-thrombi in small arterioles and/or arteries. 
The active and chronic lesions both existed in these patients.

We further analyzed the possible causes of renal TMA in lupus nephritis. Among the 36 patients, there were several clear clinical reasons for renal TMA as follows: 2 patients combining with TTP-HUS, 2 patients combining with APS, 2 patients with malignant hypertension, 1 patient with scleroderma and the other 29 patients presenting with isolated renal TMA. The other potential causes of renal TMA included 19 patients with C4d deposition on renal vascular walls, 2 patients with decreased ADAMTS-13 activity, and 17 patients with decreased serum complement factor $\mathrm{H}$. The ratio of patients with $\mathrm{C} 4 \mathrm{~d}$ deposition or decreased serum factor $\mathrm{H}$ was high. There was no significant correlation between the two risk factors $(\mathrm{r}=0.088$, $P=0.610$ ). All of the 36 patients with renal TMA were serum cryoglobulin negative.

The treatment algorithm was listed as follows. All of the patients received oral prednisone therapy $(0.8$ to $1 \mathrm{mg} /$ $\mathrm{kg} / \mathrm{d}$ or equivalent for four to six weeks and tapered slowly to a maintenance dose of 5 to $10 \mathrm{mg} / \mathrm{d}$ ). A total of 19 patients received plasma exchange, including 2 patients with TTP-HUS, 1 with catastrophic antiphospholipid antibody syndrome, 3 with lupus encephalopathy, 13 with severe crescentic glomerulonephritis, fibrinoid necrosis and thrombotic microangiopathy in renal pathological changes, and 26 patients received methylprednisolone pulse therapy. The majority of patients completed treatment with oral cyclophosphamide (5/36) or monthly intravenous cyclophosphamide (600 to $800 \mathrm{mg} /$ month) $(25 / 36)$. The other patients received mycophenolate mofetil (3/36), leflunomide (2/36) and azathioprine (1/36). Twenty patients achieved clinical remission, 8 with complete remission and 12 with partial remission. Sixteen patients presented with treatment failure. Most of the patients received immunosuppressive therapy, but the responses to the treatment were not satisfactory.

\section{Clinical and laboratory parameters}

We further compared the clinical and laboratory characteristics of patients with and without renal TMA in lupus nephritis. The clinical and laboratory features of patients in the two groups were listed in Tables 2 and 3. The patients in the renal TMA group were younger than the patients in the non-renal TMA group $(29.75 \pm 9.24$ vs. $34.38 \pm 11.95$ years, $P=0.035$ ) at the time of biopsy. There was a significantly higher ratio of nephrotic syndrome in the renal TMA group than in the non-renal TMA group ( $83.3 \%$ vs. $58.9 \%, P=0.008$ ). In laboratory findings, there were significantly higher urine protein levels $(7.09 \pm 4.64$ vs. $4.75 \pm 3.13 \mathrm{~g} / 24 \mathrm{~h}, P=0.007)$ and higher serum creatinine levels $(159,86$ to 215 vs. 81,68 to $112 \mu \mathrm{mol} / \mathrm{l}, P<0.001$ ) in the renal TMA group compared with patients in the non-renal TMA group. The TMA group presented with more severe renal injury than the control group.

\section{Renal histopathological evaluation}

Renal pathological parameters were then compared between the two groups. The distribution of renal pathological types and the characteristics of renal histopathology of the two groups were listed in Table 4. The proportion of Class IV was significantly higher in the renal TMA group than that in the non-renal TMA group $(83.3 \%$ vs. $58.0 \%, P=0.006)$. In comparison with the non-renal TMA group, patients with renal TMA had significantly higher scores of total AI $(P<0.001)$, endocapillary hypercellualrity $(P<0.001)$, subendothelial hyaline deposits $(P=0.003)$, interstitial inflammation $(P=0.005)$, glomerular leukocyte infiltration $(P=0.006)$, total CI $(P=0.033)$, tubular atrophy $(P=0.004)$ and interstitial fibrosis $(P=0.018)$, respectively. Also, the results indicated more active and chronic renal involvement in patients with renal TMA.

\section{Treatment and outcome}

Lastly, the therapy algorithm and long-term outcomes were analyzed between the two groups. The treatment and outcomes of renal TMA and non-renal TMA patients were detailed in Table 5. The ratios of patients using plasma exchange and methylprednisolone pulse were significantly higher in TMA group than that in non-TMA group $(P<0.001, P<0.001$, respectively). The renal TMA

Table 2 Comparison of clinical data between lupus nephritis patients with and without renal TMA

\begin{tabular}{cccc}
\hline & LN with renal TMA & LN without renal TMA & P-value \\
\hline Number of patients & 36 & 112 & $34.38 \pm 11.95$ \\
Age (mean \pm SD)(years) & $29.75 \pm 9.24$ & $16 / 96$ & 0.035 \\
Gender (male/female) & $10 / 26$ & $33(29.5)$ & 0.064 \\
Number of fever (non-infection) (\%) & $10(27.8)$ & $8(7.1)$ & 0.846 \\
Number of neurologic disorder (\%) & $3(8.3)$ & $79(70.5)$ & 0 \\
Number of anemia (\%) & $28(77.8)$ & $30(26.8)$ & 0.398 \\
Number of thrombocytopenia (\%) & $15(41.7)$ & $87(77.7)$ & 0.091 \\
Number of hematuria (\%) & $31(86.1)$ & $66(58.9)$ & 0.274 \\
Number of nephrotic syndrome (\%) & $30(83.3)$ & $17.62 \pm 5.68$ & 0.008 \\
SLEDAl (mean \pm SD) & $17.02 \pm 5.60$ & 0.668 \\
\hline
\end{tabular}


Table 3 Comparison of laboratory data between lupus nephritis patients with and without renal TMA

\begin{tabular}{|c|c|c|c|}
\hline & LN with renal TMA & LN without renal TMA & $P$-value \\
\hline Number of patients & 36 & 112 & \\
\hline Hemoglobin (mean $\pm \mathrm{SD}$ ) $(\mathrm{g} / \mathrm{l})$ & $92.33 \pm 22.03$ & $101.29 \pm 25.29$ & 0.059 \\
\hline Urine protein (mean $\pm \mathrm{SD}$ ) (g/24hours) & $7.09 \pm 4.64$ & $4.75 \pm 3.13$ & 0.007 \\
\hline Serum creatinine (median; inter-quartile range) $(\mu \mathrm{mol} / \mathrm{l})$ & $\begin{array}{c}159.00 \\
86.00,215.00\end{array}$ & $\begin{array}{c}81.50 \\
68.00,111.50\end{array}$ & $<0.001$ \\
\hline Number of positive ANA (\%) & $36(100)$ & $111(99.1)$ & 1.0 \\
\hline Number of positive anti-dsDNA (\%) & $28(77.8)$ & $85(75.9)$ & 0.817 \\
\hline Number of positive anti-cardiolipin (\%) & $1(2.8)$ & $7(6.2)$ & 0.680 \\
\hline Number of positive anti- $\beta 2$ GP-I (\%) & $1(2.8)$ & $8(7.1)$ & 0.688 \\
\hline C3 (mean \pm SD) $(\mathrm{mg} / \mathrm{ml})$ & $0.51 \pm 0.29$ & $0.59 \pm 0.34$ & 0.210 \\
\hline
\end{tabular}

patients presented with significant lower ratios of partial remission $(33.3 \%$ vs. $58.0 \%, P=0.01)$ and higher ratios of treatment failure $(44.4 \%$ vs. $15.2 \%, P<0.001)$ compared with the non-renal TMA group.

In our cohort study, the lupus patients with renal TMA were followed up for a period of $53 \pm 64$ months (range 6 to 240 months). The patients without renal TMA were followed up for a period of $53 \pm 44$ months (range 6 to 282 months). During the similar follow-up time, the relapse rate showed no significant difference between the two groups.

The long-term survival was similar between the two groups. But the renal outcome was significantly poorer in the TMA group $(P=0.005$, Figure 1$)$. In the TMA group (Group 1), no patients died or reached ESRD, but 10 patients reached the doubling of serum creatinine. In the non-TMA group (Group 2), one patient died, no patient reached ESRD and seven patients reached the doubling of serum creatinine.

Using the log-rank test for univariate survival analysis of renal prognosis in all the patients with lupus nephritis, we found that renal TMA was a risk factor for renal outcome in lupus nephritis $(P=0.009)$. Other univariate risk factors included sex (male, $P=0.01$ ), serum creatinine value $(P<0.001)$, proteinuria $(P=0.032)$, total activity indices score $(P=0.001)$ and total chronicity indices score $(P$ $<0.001$ ) (Details in Table 6). Multivariate analysis revealed that renal TMA (HR: 2.772, 95\% confidence interval: 1.009 to $7.617, P=0.048$ ) and serum creatinine value (HR: $1.003,95 \%$ confidence interval: 1.002 to $1.005, P<0.001$ ) were independent prognostic factors for renal survival (Additional file 3, Table S1). With further analysis, we found that the patients with both C4d deposition and decreased serum factor $\mathrm{H}$ (Group 1) presented with higher

Table 4 Comparison of renal pathological data between lupus nephritis patients with and without renal TMA

\begin{tabular}{|c|c|c|c|}
\hline & LN with renal TMA & LN without renal TMA & $P$-value \\
\hline Number of biopsies & 36 & 112 & \\
\hline Class II (\%) & $0(0)$ & $5(4.5)$ & 0.336 \\
\hline Class III (\%) & $3(8.3)$ & $26(23.2)$ & 0.05 \\
\hline Class IV (\%) & $30(83.3)$ & $65(58.0)$ & 0.006 \\
\hline Class V (\%) & $3(8.3)$ & $16(14.3)$ & 0.567 \\
\hline Al score (mean \pm SD) & $10.78 \pm 4.16$ & $7.58 \pm 4.29$ & $<0.001$ \\
\hline Endocapillary hypercellualrity (mean \pm SD) & $2.78 \pm 0.59$ & $2.20 \pm 0.99$ & $<0.001$ \\
\hline Cellular crescents (mean \pm SD) & $2.06 \pm 1.94$ & $1.38 \pm 1.8$ & 0.055 \\
\hline Karyorrhexis/fibrinoid necrosis (mean \pm SD) & $1.28 \pm 1.06$ & $0.95 \pm 1.18$ & 0.137 \\
\hline Subendothelial hyaline deposits (mean \pm SD) & $1.72 \pm 1.09$ & $1.10 \pm 1.07$ & 0.003 \\
\hline Interstitial inflammation (mean \pm SD) & $1.63 \pm 0.83$ & $1.19 \pm 0.72$ & 0.005 \\
\hline Glomerular leukocyte infiltration (median; inter-quartile range) & $\begin{array}{c}1 \\
1,2\end{array}$ & $\begin{array}{c}1 \\
0,1\end{array}$ & 0.006 \\
\hline $\mathrm{Cl}$ score $($ mean $\pm \mathrm{SD})$ & $3.67 \pm 1.91$ & $2.80 \pm 2.15$ & 0.033 \\
\hline Glomerular sclerosis (mean \pm SD) & $0.53 \pm 0.70$ & $0.48 \pm 0.70$ & 0.733 \\
\hline Fibrous crescents (median; inter-quartile range) & $\begin{array}{c}0 \\
0,1\end{array}$ & $\begin{array}{c}0 \\
0,0\end{array}$ & 0.166 \\
\hline Tubular atrophy (mean \pm SD) & $1.47 \pm 0.61$ & $1.06 \pm 0.77$ & 0.004 \\
\hline Interstitial fibrosis (mean \pm SD) & $1.36 \pm 0.59$ & $1.02 \pm 0.79$ & 0.018 \\
\hline
\end{tabular}


Table 5 Comparison of treatment data between lupus nephritis patients with and without renal TMA

\begin{tabular}{|c|c|c|c|}
\hline & LN with renal TMA & $\begin{array}{c}\text { LN without renal } \\
\text { TMA }\end{array}$ & $P$-value \\
\hline $\begin{array}{l}\text { Number of } \\
\text { patients (\%) }\end{array}$ & 36 & 112 & \\
\hline \multicolumn{4}{|l|}{ Treatment } \\
\hline $\begin{array}{l}\text { PE (Number of } \\
\text { patients (\%)) }\end{array}$ & $19(52.8)$ & $7(6.25)$ & $<0.001$ \\
\hline $\begin{array}{l}\text { MP (Number of } \\
\text { patients (\%)) }\end{array}$ & $26(72.2)$ & $18(16.1)$ & $<0.001$ \\
\hline$P$ & $36(100)$ & $112(100)$ & 1 \\
\hline CYC & $30(83.3)$ & 88 (78.6) & 0.536 \\
\hline AZA & $1(2.8)$ & $5(4.5)$ & 1 \\
\hline MMF & $3(83.3)$ & $11(9.8)$ & 1 \\
\hline LEF & $2(5.6)$ & $8(7.1)$ & 1 \\
\hline \multicolumn{4}{|l|}{$\begin{array}{l}\text { Treatment } \\
\text { response }\end{array}$} \\
\hline$C R$ & $8(22.2)$ & $30(26.8)$ & 0.586 \\
\hline$P R$ & $12(33.3)$ & $65(58.0)$ & 0.01 \\
\hline TF & $16(44.4)$ & $17(15.2)$ & $<0.001$ \\
\hline $\begin{array}{l}\text { Duration of } \\
\text { follow-up (m) }\end{array}$ & $53(6,240)$ & $53(6,282)$ & 0.15 \\
\hline Relapse rate & $\begin{array}{l}4 \text { (4/20, } 20 \% \text {, } 3 \text { with } \\
\text { nephritic relapse } \\
\text { and } 1 \text { with } \\
\text { proteinuric relapse) }\end{array}$ & $\begin{array}{l}17 \text { (17/95, 17.89\%, } \\
15 \text { with nephritic } \\
\text { relapse and } 2 \text { with } \\
\text { proteinuric relapse) }\end{array}$ & 0.543 \\
\hline
\end{tabular}

AZA, azathioprine; CR, complete remission; CYC, cyclophosphamide; LEF, leflunomide; MMF, mycophenolate mofetil; MP, methylprednisolone impulse; $\mathrm{P}$, oral prednisone; $\mathrm{PE}$, plasma exchange; $\mathrm{PR}$, partial remission; $\mathrm{TF}$, treatment failure

pathological AI scores $(13.44 \pm 3.78$ vs. $9.89 \pm 3.95$, $P=0.024)$ and poorer renal outcome $(P=0.007$, Figure 2$)$ compared with those without the combination in the TMA group (Group 2).

Taking the above results together, although with more intensive immunosuppressive therapy, patients with TMA had a poorer renal outcome, especially those with both $\mathrm{C} 4 \mathrm{~d}$ deposition and decreased serum factor $\mathrm{H}$, than those without renal TMA.

\section{Discussion}

The prevalence of renal TMA, including acute and chronic changes, in our cohort with lupus nephritis was $24.3 \%$ (36/ $148)$, which was higher than that in previous studies $(0.5 \%$ to $10 \%)[2,24]$. The most possible reason might be that our diagnosis was based on the strict histopathological criteria, not just clinical evaluation, which might increase the ratio. In fact, diagnosis of TMA in SLE is sometimes difficult because these two disorders share similar clinical features, including anemia, thrombocytopenia, neurological deficits, renal involvement and fever. Therefore, the pathological criteria should be regarded as the "gold standard" in patients with SLE.

As reported in the previous studies [25-27], patients with both renal TMA and lupus nephritis in our center presented with more severe renal injury features, including a higher amount of proteinuria, higher value of serum creatinine, higher scores of total AI indices, endocapillary hypercellualrity, cellular crescents, subendothelial hyaline deposits, interstitial inflammation, glomerular leukocyte infiltration, total CI indices, tubular atrophy and interstitial fibrosis in pathological evaluations, compared with the patients without TMA. Although with more intensive immunosuppressive therapy, patients with TMA had a poorer renal outcome than those without renal TMA. Renal TMA was found as an independent risk factor for renal outcome in lupus nephritis.

The pathogenesis of renal TMA in lupus nephritis remains unclear and may be multifactorial, which might be attributed to APS, TTP-HUS, malignant hypertension, pregnancy, scleroderma, drugs and so on. Thus, we further investigated the above risk factors in the 36 renal TMA patients. Interestingly, only seven patients were found with clear reasons, including two with TTP-HUS, two with APS, two with malignant hypertension and one with scleroderma. The other 29 patients only presented with pathological evidence of renal TMA.

It is suggested that immune complex-mediated complement activation via the classical pathway plays a key role in the pathogenesis of tissue injury in lupus nephritis [28-30]. C4d is produced mainly through the classical complement activation cascade and can covalently bind to glomerular endothelial surfaces and basement membranes through the thiol ester site [31]. Recently, Danielle et al. [5] and Shen et al. [32] found that positive C4d staining in glomeruli correlated with the development of renal microthrombi and demonstrated that activation of the complement classical pathway might be a crucial factor in the development of TMA in lupus nephritis. In our study, we also found that a high ratio (19/36) of patients had C4d deposition on vessels in patients with renal TMA. Li et al. [33] recently reported that C4d deposition in peritubular capillaries was closely related with low serum C4 level and higher disease activity of lupus nephritis. It is possible that although it intend to clear the immune complexes, the activation of complement classical pathway may further cause the inflammation and injury of the endothelium. Because C4d is also involved in the lectin pathway, we cannot exclude the possibility that $\mathrm{C} 4 \mathrm{~d}$ deposition partly reflects activation of the mannose-binding lectin (MBL) pathway, which needs further investigation.

Although it has been suggested that the development of SLE, especially lupus nephritis, is closely associated with immune complex-induced complement activation via classical pathways, recent studies [34] demonstrated that activation of the alternative complement pathway could accurately reflect disease activity and the ongoing activation 


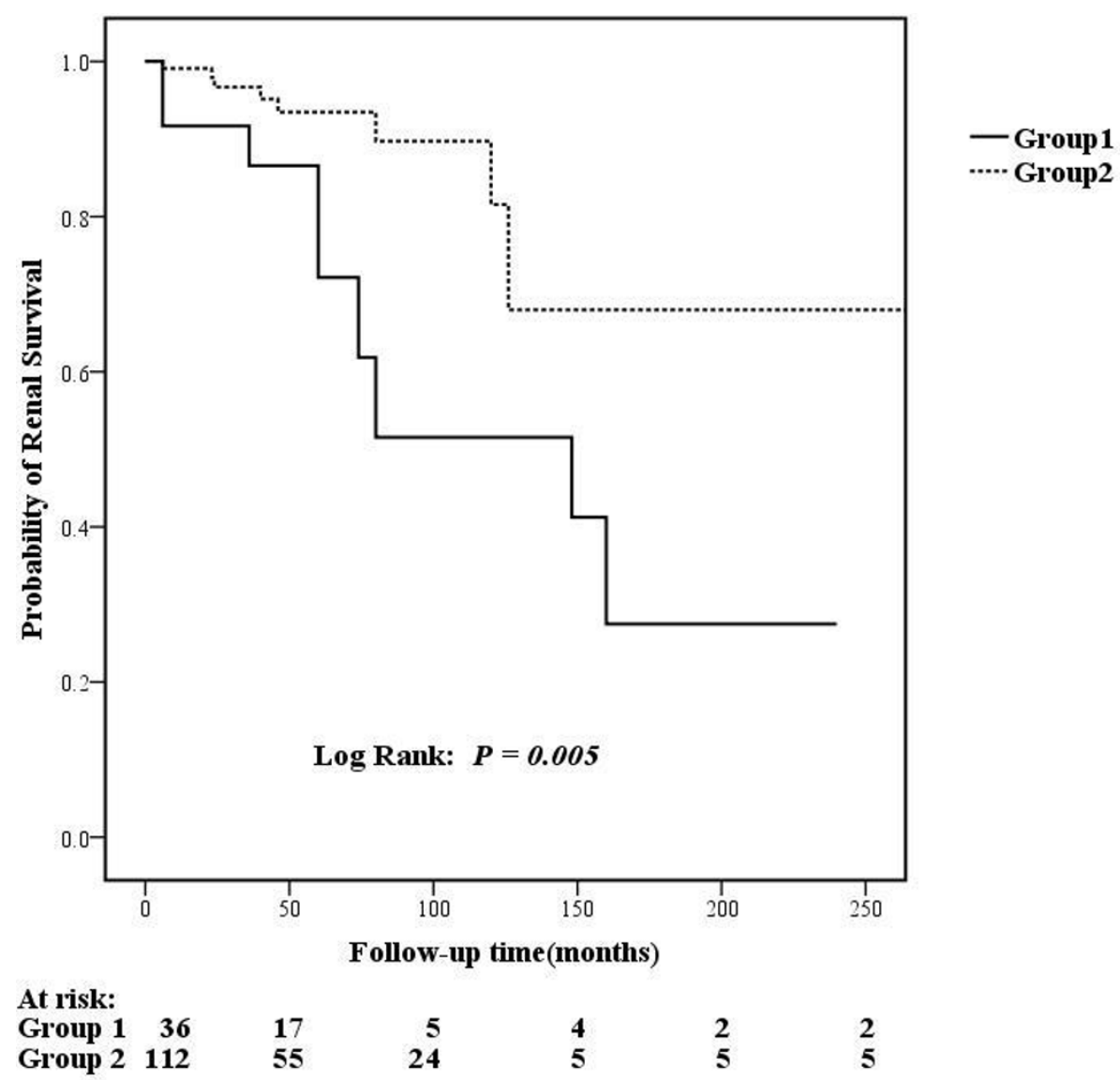

Figure 1 Comparison of renal outcomes between lupus nephritis patients with and without renal TMA.

paralleled with flares in patients with SLE, and the alternative pathway might play an important role in complement activation-induced self-injury and inflammatory response in SLE [35]. Further studies suggested that patients with deficiency of complement regulators, such as complement factor $\mathrm{H}$, of the alternative pathway, was susceptible to SLE [36-38]. A recent study has shown that factor $\mathrm{H}$ deficiency accelerates the development of lupus nephritis in lupus-

Table 6 Univariate survival analysis of patients' renal prognosis with lupus nephritis

\begin{tabular}{lcccc}
\hline & HR & 95\% confidence interval & P-value \\
\hline Age & 0.947 & 0.896 & 1.002 & 0.057 \\
Sex & 0.252 & 0.089 & 0.717 & 0.010 \\
Proteinuria & 1.109 & 1.009 & 1.220 & 0.032 \\
Serum creatinine value & 1.003 & 1.002 & 1.005 & $<.001$ \\
ANA & 0.049 & 0.000 & 0.000 & 0.912 \\
Anti-ds-DNA antibody & 0.970 & 0.353 & 2.664 & 0.953 \\
SLEDAl & 0.961 & 0.885 & 1.043 & 0.344 \\
Activity indices (Al) score & 1.220 & 1.080 & 1.378 & 0.001 \\
Chronicity indices (Cls) score & 1.428 & 1.191 & 1.713 & $<.001$ \\
Renal TMA & 0.275 & 0.105 & 0.721 & 0.009 \\
Anti-cardiolipin antibody & 23.596 & 0.012 & 45,236 & 0.412 \\
anti-B2GP-1 antibody & 25.022 & 0.001 & 647,548 & 0.535 \\
ADAMTS13 activity & 1.542 & 0.161 & 14.764 & 0.707 \\
Complement factor H & 0.998 & 0.996 & 1.001 & 0.247 \\
Vascular C4d deposition & 0.815 & 0.320 & 2.078 & 0.669 \\
\hline
\end{tabular}




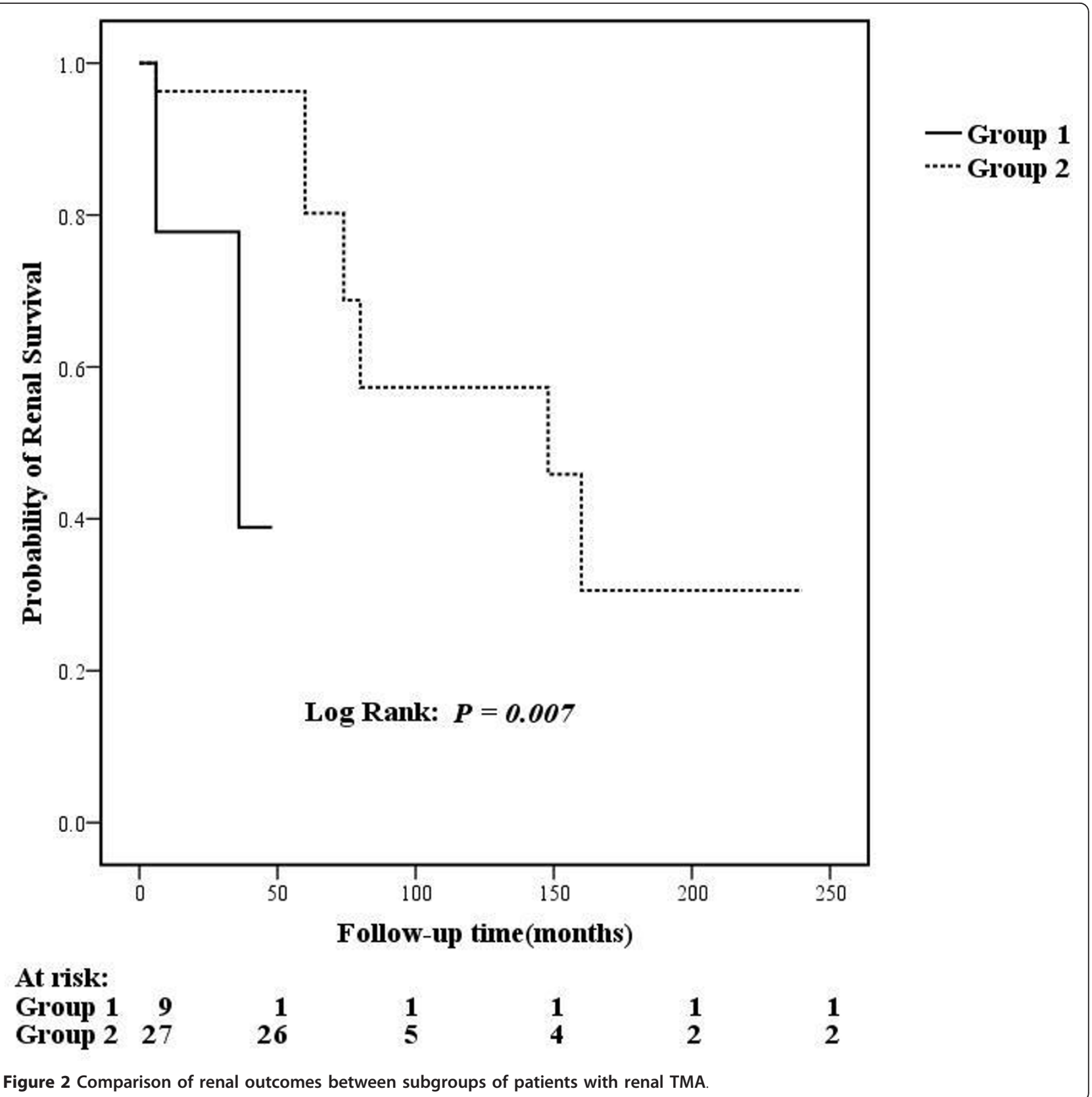

prone mice MRL-lpr [39]. As mutations and single nucleotide polymorphisms (SNPs) in complement factor $\mathrm{H}$ have been implicated in a variety of human pathological conditions, especially atypical hemolytic uremic syndrome (aHUS), one of the reasons for TMA, we further detected concentrations of serum factor $\mathrm{H}$ in our patients. Interestingly, nearly half of the patients in our renal TMA group were found with decreased serum complement factor $\mathrm{H}$. Complement factor $\mathrm{H}$ is a fluid phase complement regulator of the alternative complement pathway $[40,41]$. It can bind to endothelial cells and protects them from being attacked by the complement system. It is suggested that dysfunction or reduced levels of serum factor $\mathrm{H}$ may cause endothelial cell damage which may be followed by platelet consumption, red cell damage and the final TMA [42]. The potential reasons for lower factor $\mathrm{H}$ in renal TMA with lupus nephritis, including autoantibodies against factor $\mathrm{H}$ or factor $\mathrm{H}$ gene mutations, need further study.

Furthermore, we divided TMA patients into two groups based on C4d deposition in the kidney and the value of serum factor $\mathrm{H}$, and found that the patients with both $\mathrm{C} 4 \mathrm{~d}$ deposition and decreased serum complement factor $\mathrm{H}$ 
presented with higher pathological AI scores and poorer renal outcome. The results supported that over-activation of both complement classic and alternative pathways might aggravate TMA injury in lupus nephritis. Previous studies also suggested that classic pathway activation can recruit the potent components to further amplify generation of $\mathrm{C} 3$ and $\mathrm{C} 5$ activation products and alternative pathway activation might hold the key to continuous tissue damage via the amplification loop in kidney situ in lupus nephritis [43].

Tissue factor is an inducer of thrombosis. Interestingly, recent studies strengthened the idea that tissue factor activation which can be induced by the activation of complement, might be important in the pathogenesis of TMA $[44,45]$.

We also observed that the ratio of nephrotic syndrome and the amount of proteinuria were both higher in the TMA group than that in the pure lupus nephritis group. As proteinuria might be a risk factor for thromboembolism, owing to loss of plasma antithrombin III and activation of the coagulation system [46,47], further studies were needed to confirm the pathogenetic role of proteinuria in renal TMA.

Many studies, including experimental models [48,49] and clinical observations [50], have shown complement activation to be essential in TMA. So our findings hold promise for complement inhibition as a therapeutic approach in the further treatment of TMA with lupus nephritis.

\section{Conclusions}

In conclusion, there were various causes of renal TMA in lupus nephritis. TMA was an independent risk factor for renal outcome in lupus nephritis. Our study highlights the status of both complement classic and alternative pathway activation in the pathogenesis of renal TMA in lupus nephritis.

\section{Additional material}

\section{Additional file 1: Figure S1. Renal TMA identified by electron}

microscopy. (A) Electron micrograph showed glomerular endothelial cell proliferation with narrowed capillary lumen, and widening of subendothelial space with electron dense deposits and infiltration of monocyte $(E M \times 5,000)$. (B) Higher magnification of part of Figure $A$, subendothelial widening with lucent area and electron dense deposits $(\mathrm{EM} \times 20,000)$

Additional file 2: Figure S2. Renal TMA identified by light microscopy and C4d staining on renal vessels. (A-C)Thrombotic microangiopathy superimposed on lupus nephritis: (A) Glomerular endocapillary hypercellularity with intraluminal thrombus (Masson's trichrome $\times 400$ ). (B) Thrombosis in interlobular arteriole (Periodic AcidSilver Methenamine and Masson's trichrome $\times 400)($ C) The thickened arteriole with swelling of endothelial cells and intimal fibrosis (Periodic Acid-Silver Methenamine and Masson's trichrome $\times 400$ ). (D) C4d is positive beneath the vascular endothelium and within the basement membrane around the medial myocytes in patient with lupus nephritis (Original magnification $\times 400$ ).

Additional file 3: Table S.1 Multivariate survival analysis of patients' renal prognosis with lupus nephritis. Renal TMA and serum creatinine value were independent prognostic factors for renal survival.

\section{Abbreviations}

ADAMTS-13: a disintegrin and metalloprotease with thrombospondin type I repeats 13; aHUS: atypical hemolytic uremic syndrome; Al: activity indices; ANA: antinuclear antibodies; APS: anti-phospholipid syndrome; CFH: complement factor $\mathrm{H}$; Cl: chronicity indices; ds-DNA: double-stranded DNA; ELISA: enzyme-linked immunosorbent assay; ENA: extractable nuclear antigen; ESRD: end stage renal disease; H\&E: hematoxylin and eosin; HR: hazard ratio; MBL: mannose-binding lectin; Meth: silver methenamine; PAS: periodic acid-Schiff; SLE: systemic lupus erythematosus; SLEDAI: systemic lupus erythematosus disease activity index; SNPs: single nucleotide polymorphisms; TMA: thrombotic microangiopathy; TTP-HUS: thrombotic thrombocytopenic purpura-hemolytic uremic syndrome.

\section{Authors' contributions}

DS performed sample tests, analyzed data and wrote the manuscript. LHW and GL performed renal histopathological evaluation. FMW, XWY and DZ performed sample tests. MC collected clinical data on patients. FY recruited patients, collected samples and collected clinical data from patients, and designed and directed the study. MHZ designed and directed the study. All authors read and approved the manuscript for publication.

\section{Competing interests}

The authors declare that they have no competing interests.

\section{Acknowledgements}

We gratefully acknowledge the contributions of Su-xia WANG, Jie AO, Xin ZHENG and Lei QU at Peking University First Hospital for histopathological study.

This work was supported by grants from Chinese 973 project (No. 2012CB517702), National Natural Science Foundation of China to Innovation Research Group (No. 81021004), National Natural Science Foundation of China (No. 81100497), and "National Key Technology Research and Development (R\&D) Program" of the Ministry of Science and Technology of China (No. 2011BAl10B04).

\section{Author details}

${ }^{1}$ Renal Division, Department of Medicine, Peking University, First Hospital, Peking University Institute of Nephrology, Key Laboratory of Renal Disease, Ministry of Health of China, Key Laboratory of Chronic Kidney Disease Prevention and Treatment, Ministry of Education of China, Beijing 100034, PR China. ${ }^{2}$ Department of Nephrology, General Hospital of Ningxia Medical University, Ningxia 750004, PR China.

Received: 20 August 2012 Revised: 4 December 2012 Accepted: 7 January 2013 Published: 15 January 2013

\section{References}

1. Cameron JS: Lupus nephritis. J Am Soc Nephrol 1999, 10:413-424.

2. Banfi G, Bertani T, Boeri V, Faraggiana T, Mazzucco G, Monga G, Sacchi G: Renal vascular lesions as a marker of poor prognosis in patients with lupus nephritis. Gruppo Italiano per lo Studio della Nefrite Lupica (GISNEL). Am J Kidney Dis 1991, 18:240.

3. Appel G, Pirani C, D'Agati V: Renal vascular complications of systemic lupus erythematosus. J Am Soc Nephrol 1994, 4:1499-1515.

4. Lansigan F, Isufi I, Tagoe CE: Microangiopathic haemolytic anaemia resembling thrombotic thrombocytopenic purpura in systemic lupus erythematosus: the role of ADAMTS13. Rheumatology 2011, 50:824-829.

5. Cohen D, Koopmans M, Kremer Hovinga IC, Berger SP, Roos van Groningen M, Steup-Beekman GM, de Heer E, Bruijn JA, Bajema IM: Potential for glomerular C4d as an indicator of thrombotic microangiopathy in lupus nephritis. Arthritis Rheum 2008, 58:2460-2469. 
6. Hochberg MC: Updating the American College of Rheumatology revised criteria for the classification of systemic lupus erythematosus. Arthritis Rheum 1997, 40:1725.

7. Liang MH, Socher SA, Larson MG, Schur PH: Reliability and validity of six systems for the clinical assessment of disease activity in systemic lupus erythematosus. Arthritis Rheum 1989, 32:1107-1118.

8. Bombardier C, Gladman DD, Urowitz MB, Caron D, Chang CH: Derivation of the SLEDAl: a disease activity index for lupus patients The Committee on Prognosis Studies in SLE. Arthritis Rheum 1992, 35:630-640.

9. Wilson WA, Gharavi AE, Koike T, Lockshin MD, Branch DW, Piette JC, Brey R, Derksen R, Harris EN, Hughes GR: International consensus statement on preliminary classification criteria for definite antiphospholipid syndrome. Arthritis Rheum 1999, 42:1309-1311.

10. Wang J, Hu W, Xie H, Zhang H, Chen H, Zeng C, Liu Z, Li L: Induction therapies for Class IV lupus nephritis with non-inflammatory necrotizing vasculopathy: mycophenolate mofetil or intravenous cyclophosphamide. Lupus 2007, 16:707-712.

11. Ginzler EM, Dooley MA, Aranow C, Kim MY, Buyon J, Merrill JT, Petri M, Gilkeson GS, Wallace DJ, Weisman MH: Mycophenolate mofetil or intravenous cyclophosphamide for lupus nephritis. N Engl J Med 2005 353:2219-2228.

12. Chan T, Tse K, Tang CSO, Lai K, Li F: Long-term outcome of patients with diffuse proliferative lupus nephritis treated with prednisolone and oral cyclophosphamide followed by azathioprine. Lupus 2005, 14:265-272.

13. Wang H, Cui T, Hou F, Ni Z, Chen X, Lu F, Xu F, Yu X, Zhang F, Zhao X: Induction treatment of proliferative lupus nephritis with leflunomide combined with prednisone: a prospective multi-centre observational study. Lupus 2008, 17:638-644.

14. Szczepiorkowski ZM, Winters JL, Bandarenko N, Kim HC, Linenberger ML, Marques MB, Sarode R, Schwartz J, Weinstein R, Shaz BH, Apheresis Applications Committee of the American Society for Apheresis: Guidelines on the use of therapeutic apheresis in clinical practice-evidence-based approach from the apheresis applications committee of the American Society for Apheresis. J Clin Apher 2010, 25:83-177.

15. Contreras G, Pardo V, Leclerca B, Lenz O, Tozman E, O'Nan P, Roth D: Sequential therapies for proliferative lupus nephritis. N Engl J Med 2004, 350:971-980.

16. Grootscholten C, Ligtenberg G, Hagen EC, van den Wall Bake AW, de Glas-Vos JW, Bijl M, Assmann KJ, Bruijn JA, Weening JJ, van Houwelingen HC, Derksen RH, Berden JH, Dutch Working Party on Systemic Lupus Erythematosus: Azathioprine/methylprednisolone versus cyclophosphamide in proliferative lupus nephritis. A randomized controlled trial. Kidney Int 2006, 70:732-742.

17. Zhang JJ, Jiang L, Liu G, Wang SX, Zou WZ, Zhang H, Zhao MH: Levels of urinary complement factor $\mathrm{H}$ in patients with IgA nephropathy are closely associated with disease activity. Scand J Immunol 2009, 69:457-464.

18. Yu F, Tan Y, Zhao MH: Lupus nephritis combined with renal injury due to thrombotic thrombocytopaenic purpura-haemolytic uraemic syndrome. Nephrol Dial Transplant 2010, 25:145-152

19. Weening JJ, D'Agati VD, Schwartz MM, Seshan SV, Alpers CE, Appel GB, Balow JE, Bruijn JA, Cook T, Ferrario F, Fogo AB, Ginzler EM, Hebert L, Hill G, Hill $P$, Jennette JC, Kong NC, Lesavre P, Lockshin M, Looi LM, Makino H, Moura LA, Nagata M, International Society of Nephrology Working Group on the Classification of Lupus Nephritis; Renal Pathology Society Working Group on the Classification of Lupus Nephritis: The classification of glomerulonephritis in systemic lupus erythematosus revisited. Kidney Int 2004, 65:521-530.

20. Austin HA, Boumpas DT, Vaughan EM, Balow JE: Predicting renal outcomes in severe lupus nephritis: contributions of clinical and histologic data. Kidney Int 1994, 45:544-550.

21. Austin HA, Muenz LR, Joyce KM, Antonovych TT, Balow JE: Diffuse proliferative lupus nephritis: identification of specific pathologic features affecting renal outcome. Kidney Int 1984, 25:689-695.

22. Xing GQ, Chen M, Liu G, Heeringa P, Zhang JJ, Zheng X, Jie E, Kallenberg CG, Zhao MH: Complement activation is involved in renal damage in human antineutrophil cytoplasmic autoantibody associated pauci-immune vasculitis. J Clin Immunol 2009, 29:282-291.

23. Galindo M, Gonzalo E, Martinez-Vidal MP, Montes S, Redondo N, Santiago B, Loza E, Pablos JL: Immunohistochemical detection of intravascular platelet microthrombi in patients with lupus nephritis and antiphospholipid antibodies. Rheumatology 2009, 48:1003-1007.

24. Tsumagari T, Fukumoto S, Kinjo M, Tanaka K: Incidence and significance of intrarenal vasculopathies in patients with systemic lupus erythematosus. Hum Pathol 1985, 16:43-49.

25. Vasoo S, Thumboo J, Fong KY: Thrombotic thrombocytopenic purpura in systemic lupus erythematosus: disease activity and the use of cytotoxic drugs. Lupus 2002, 11:443-450.

26. Letchumanan $P, N g ~ H J$, Lee $L H$, Thumboo J: A comparison of thrombotic thrombocytopenic purpura in an inception cohort of patients with and without systemic lupus erythematosus. Rheumatology 2009, 48:399-403.

27. Silvariño R, Sant F, Espinosa G, Pons-Estel G, Solé M, Cervera R, Arrizabalaga P: Nephropathy associated with antiphospholipid antibodies in patients with systemic lupus erythematosus. Lupus 2011, 20:721-729.

28. Tang S, Lui SL, Lai KN: Pathogenesis of lupus nephritis: an update. Nephrology 2005, 10:174-179.

29. Liu CC, Ahearn JM, Manzi S: Complement as a source of biomarkers in systemic lupus erythematosus: past, present, and future. Curr Rheumatol Rep 2004, 6:85-88.

30. Valentijn RM, van Overhagen $H$, Hazevoet HM, Hermans J, Cats A, Daha MR, van Es LA: The value of complement and immune complex determinations in monitoring disease activity in patients with systemic lupus erythematosus. Arthritis Rheum 1985, 28:904-913.

31. Feucht HE, Opelz G: The humoral immune response towards HLA Class II determinants in renal transplantation. Kidney Int 1996, 50:1464-1475.

32. Shen $Y$, Chen $X$, Sun $C$, Dai $M$, Yan $Y$, Yang C: Association between anti- $\beta 2$ glycoprotein I antibodies and renal glomerular C4d deposition in lupus nephritis patients with glomerular microthrombosis: a prospective study of 155 cases. Lupus 2010, 19:1195-1203.

33. Li S, Liu Z, Zen C, Wang Q, Wang Y, Li L: Peritubular capillary C4d deposition in lupus nephritis different from antibody-mediated renal rejection. Lupus 2007, 16:875-880

34. Watanabe H, Garnier G, Circolo A, Wetsel RA, Ruiz P, Holers VM, Boackle SA, Colten HR, Gilkeson GS: Modulation of renal disease in MRL/lpr mice genetically deficient in the alternative complement pathway factor B. J Immunol 2000, 164:786.

35. Sato N, Ohsawa I, Nagamachi S, Ishii M, Kusaba G, Inoshita H, Toki A, Horikoshi S, Ohi H, Matsushita M: Significance of glomerular activation of the alternative pathway and lectin pathway in lupus nephritis. Lupus 2011, 20:1378-1386.

36. Brai M, Misiano G, Maringhini S, Cutaja I, Hauptmann G: Combined homozygous factor $\mathrm{H}$ and heterozygous $\mathrm{C} 2$ deficiency in an Italian family. J Clin Immunol 1988, 8:50-56.

37. Sánchez-Corral P, Bellavia D, Amico L, Brai M, Rodríguez de Córdoba S: Molecular basis for factor $\mathrm{H}$ and FHL-1 deficiency in an Italian family. Immunogenetics 2000, 51:366-369.

38. Amadei N, Baracho G, Nudelman V, Bastos W, Florido M, Isaac L: Inherited complete factor I deficiency associated with systemic lupus erythematosus, higher susceptibility to infection and low levels of factor H. Scand I Immunol 2001, 53:615-621.

39. Bao L, Haas M, Quigg RJ: Complement factor $\mathrm{H}$ deficiency accelerates development of lupus nephritis. J Am Soc Nephrol 2010, 22:285-295.

40. Estaller C, Weiss EH, Schwaeble W, Dierich M: Human complement factor $\mathrm{H}$ : two factor $\mathrm{H}$ proteins are derived from alternatively spliced transcripts. Eur J Immunol 1991, 21:799-802.

41. Lee BH, Kwak SH, Shin Jl, Lee SH, Choi HJ, Kang HG, Ha IS, Lee JS, DragonDurey MA, Choi Y: Atypical hemolytic uremic syndrome associated with complement factor $\mathrm{H}$ autoantibodies and CFHR1/CFHR3 deficiency. Pediatr Res 2009, 66:336-340.

42. Józsi M, Heinen S, Hartmann A, Ostrowicz CW, Hälbich S, Richter $\mathrm{H}$, Kunert A, Licht C, Saunders RE, Perkins SJ: Factor H and atypical hemolytic uremic syndrome: mutations in the $\mathrm{C}$-terminus cause structural changes and defective recognition functions. J Am Soc Nephrol 2006, 17:170-177.

43. Bao L, Quigg RJ: Complement in lupus nephritis: the good, the bad, and the unknown. Semin Nephrol 2007, 27:69-80.

44. Ritis K, Doumas M, Mastellos D, Micheli A, Giaglis S, Magotti P, Rafail S, Kartalis G, Sideras P, Lambris JD: A novel C5a receptor-tissue factor crosstalk in neutrophils links innate immunity to coagulation pathways. J Immunol 2006, 177:4794-4802.

45. Redecha P, Tilley R, Tencati M, Salmon JE, Kirchhofer D, Mackman N, Girardi G: Tissue factor: a link between $\mathrm{C} 5$ a and neutrophil activation in 
antiphospholipid antibody-induced fetal injury. Blood 2007,

110:2423-2431

46. Citak A, Emre S, Sâirin A, Bilge I, Nayir A: Hemostatic problems and thromboembolic complications in nephrotic children. Pediatr Nephrol 2000, 14:138-142.

47. Hara T, Naito K: Inherited antithrombin deficiency and end stage renal disease. Med Sci Monit 2005, 11:346-354.

48. Pierangeli SS, Girardi G, Vega-Ostertag M, Liu X, Espinola RG, Salmon J: Requirement of activation of complement $\mathrm{C} 3$ and $\mathrm{C} 5$ for antiphospholipid antibody-mediated thrombophilia. Arthritis Rheum 2005, 52:2120-2124.

49. Nangaku M, Alpers CE, Pippin J, Shankland SJ, Kurokawa K, Adler S, Morgan B, Johnson RJ, Couser WG: CD59 protects glomerular endothelial cells from immune-mediated thrombotic microangiopathy in rats. J Am Soc Nephrol 1998, 9:590-597.

50. Lapeyraque AL, Malina M, Fremeaux-Bacchi V, Boppel T, Kirschfink M, Oualha M, Proulx F, Clermont MJ, Le Deist F, Niaudet P: Eculizumab in severe shiga-toxin-associated HUS. N Engl J Med 2011, 364:2561-2563.

doi:10.1186/ar4142

Cite this article as: Song et al:: The spectrum of renal thrombotic microangiopathy in lupus nephritis. Arthritis Research \& Therapy 201315 R12.

\section{Submit your next manuscript to BioMed Central} and take full advantage of:

- Convenient online submission

- Thorough peer review

- No space constraints or color figure charges

- Immediate publication on acceptance

- Inclusion in PubMed, CAS, Scopus and Google Scholar

- Research which is freely available for redistribution

Submit your manuscript at www.biomedcentral.com/submit 